\title{
Analíse Comparativa de Custos Entre Concreto Betuminoso Usinado a Quente (Cbuq) e Tratamento Superficial Duplo (Tsd)
}

\section{Comparative Analysis of Costs Between Bituminous Concrete Hot Mix (Cbuq) and Double Bituminous Surface Treatment (Tsd)}

\author{
Edgar dos Santos Veggi \\ Sérgio Luiz Moraes Magalhães (serjaomagalhaes@gmail.com)
}

\begin{abstract}
Enviado: Julho de 2014 Aceito: Agosto de 2014 Publicado: Outubro de 2014
Resumo: O presente trabalho aborda as características técnicas e discorre sobre análise comparativa entre Concreto Betuminoso Usinado a Quente (CBUQ) e Tratamento Superficial Duplo (TSD). A pavimentação está relacionada com o aumento da demanda do tráfego, fazendo-se necessário novas vias pavimentadas. Realiza-se comparação de custos dos revestimentos propostos, utilizando a taxa de crescimento do tráfego com base em uma contagem de tráfego simulada, próxima à realidade. As características dos pavimentos expõem as situações de uso que atendam as condicionantes para construção, conservação e manutenção. A composição de custo foi feita por meios estatísticos do Departamento Nacional de Infraestrutura e Transporte (DNIT), numa amostra a nível nacional, que assegura mais abrangência a este trabalho. Traçado o gráfico de custos dos dois revestimentos, encontra-se o break even point, em que não há divergência de custos para ambos revestimentos. O trabalho é concluído com parâmetros propostos e comparados em relação ao dimensionamento dos pavimentos e custos finais, expondo métodos econômicos para se trabalhar com pavimentação asfáltica.
\end{abstract}

Palavras-Chave: Pavimentação, Tráfego, DNIT

\begin{abstract}
This paper discusses the technical characteristics and the comparative analysis of Bituminous Concrete Hot Readymixed and Double Surface Treatment. The paving is related to the increase in traffic demand, which makes necessary new paved roads. It was carried out through this paper a costs comparison of the proposed reinvestments using the traffic growth rate, that was based in a simulated traffic count, close to reality. The pavements characteristics expose the usage situations that meet the conditionings for construction, conservation and reparation. The cost composition was made through statistic methods from the National Department of infrastructure and Transport, in a national level sample, which provides a bigger coverage for this paper. Once the costs graph for the two reinvestments was done, it was found the breakpoint, where there is no divergence in costs for both reinvestments. The paper is concluded with proposed parameters and there is a comparison between the dimensioning of pavements and final costs, and it exposes economic methods for working with asphalt paving.
\end{abstract}

Keywords: Pavement, Traffic, DNIT

\section{INTRODUÇÃO}

Este trabalho intitulado "Análise comparativa de custos entre Concreto Betuminoso Usinado a
Quente (CBUQ) e Tratamento Superficial Duplo (TSD)" foi elaborado para atender as exigências do curso de Engenharia Civil da Universidade Federal de Mato Grosso 
- UFMT, como pré-requisito para obtenção do título do grau de bacharel emEngenharia Civil.

O estudo aborda comparações das implantações dos revestimentos asfálticos, prevendo aumento nas demandas de tráfego. São considerados preços, composições de insumos e modelos de serviços do Departamento Nacional de Infraestrutura e Transporte - DNIT.

Este trabalho tem como objetivo fazer uma comparação entre o custo final dos dois tipos de revestimentos de pavimentos flexíveis, abrangendo a execução, conservação e manutenção das camadas de revestimentos asfálticos mais usuais. Quando citado neste trabalho os pavimentos de CBUQ e TSD, entendese tomá-los como as soluções iniciais.

Para atender o objetivo, faz-se o cálculo do número $\mathrm{N}$ para um dado volume de tráfego que atenda aos dois tipos de revestimentos; dimensionam-se os dois tipos de pavimentos flexíveis; identifica-se, no custo, o ponto de encontro dos diferentes revestimentos esse ponto é chamado de break even point - e compara-se, em custos finais, o CBUQ e o TSD.

O Revestimento de Concreto Betuminoso Usinado a Quente (CBUQ) vem se constituindo como solução mais adequada para garantir a

\section{Revisão Bibliográfica}

\section{Histórico Da Pavimentação}

Percorrer a história da pavimentação remete à própria história da humanidade, passando pelo povoamento dos continentes, conquistas territoriais, intercâmbio comercial, cultural e religioso, urbanização e desenvolvimento. Como os pavimentos, a história também é construída em camadas e freqüentemente as estradas formam um caminho para examinar o passado, daí serem uma das primeiras buscas dos arqueólogos nas explorações de civilizações antigas trafegabilidade nos corredores de transportes do Estado de Mato Grosso, porém a implantação desse tipo de revestimento não é, inicialmente, atrativa por conta do elevado custo. Por outro lado, devido à sua pequena espessura, o Tratamento Superficial Duplo (TSD) não contribui para a resistência estrutural, sendo um revestimento de menor durabilidade. Entretanto, seu custo de construção o torna mais econômico.

A indefinição deriva de uma cultura de gerência de pavimento que dificulta a tomada de decisão por parte dos gestores de pavimentação, quando estes confrontam as alternativas de revestimento TSD $x$ CBUQ. Buscar indicadores que auxiliem nessa tomada de decisão, justifica a escolha do tema para este Trabalho de Graduação. A adoção do revestimento de CBUQ para um período de 20 anos de projetos é mais vantajosa do que o TSD como solução inicial? As hipóteses que possam buscar resposta para a problemática: (1 ) Para espessura inicial de CBUQ de $5 \mathrm{~cm}$, o TSD é vantajoso até 10 anos; (2a) Para taxas de crescimento de $3 \%$, os custos totais se equivalem aos 14 anos; $\left(3^{\mathrm{a}}\right)$ Para a vida útil do TSD de 5 anos, a solução inicial de CBUQ será vantajosa aos 20 anos.

(BERNUCCI et al, 2008).

A invenção da roda ocorreu na Mesopotâmia, há mais de 5000 anos e gerou a necessidade da utilização de materiais mais resistentes na construção de estradas. Sabe-se muito pouco sobre as primeiras estradas construídas, mas elas datam, certamente, de antes do chamado período histórico.

Foram encontrados vestígios marcantes de antigas estradas, com suas obras de arte, na América Central, Norte e Noroeste da América do Sul, planejadas e construídas pelas civilizações Maias, Astecas e, principalmente, Incas. 
Delas, os antigos historiadores se referiam como semelhantes às romanas. Uma das mais antigas estradas de que há vestígios

Figura 1- Estrada para as Pirâmides. Fonte:

DEL BARCO, 2006

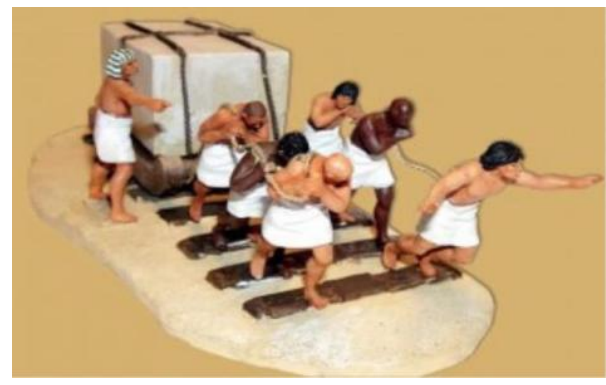

Durante o período compreendido entre os anos 400 a.C. e 200 d.C., os romanos intensificaram a construção de um abrangente sistema de estradas, compreendendo uma extensão total de mais de 75.000 milhas, que cobria todo o seu vasto Império. Vinte e nove estradas irradiavam de Roma e se conectavam com numerosas outras (PREGO, 2001).

Em algumas escavações encontra-se uma mistura de argila e areia junto aos blocos, esse material fazia a liga entre os blocos, daí a origem dos primeiros ligantes. Esse revestimento tinha espessura de 5 a 7,5 $\mathrm{cm}$, mas podendo chegar a $60 \mathrm{~cm}$ (BERNUCCI et al, 2008). A Figura 2 mostra esse modelo.

Figura 2- Via Ostiense. Fonte: BERNUCCI et al, 2008 .

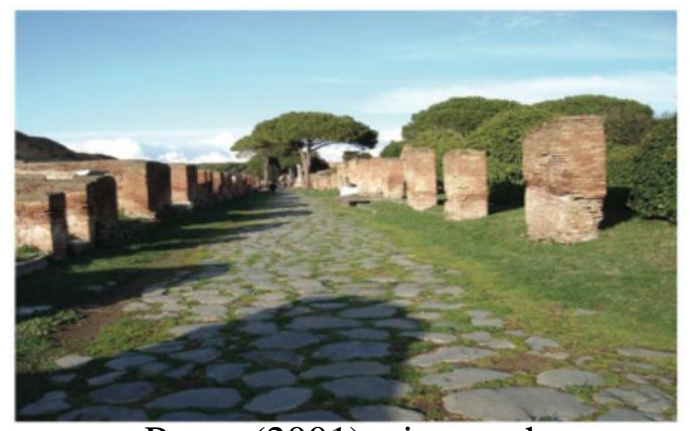

Prego (2001) cita que houve, na era moderna, as seguintes etapas de evolução para a pavimentação:

- Fase I (1595) com a descoberta de atualmente, está na Grécia. Sendo construída com pedra, provavelmente, no ano de 1500 a.C. (PREGO, 2001).

asfalto natural no lago de Trinidad dáse inicio aos estudos para utilizá-lo na pavimentação.

- Fase II (1802 - 1814) com o asfalto natural, os franceses pavimentavam grandes áreas no Palais Royal.

Napoleão reconheceu a importância econômica e militar das estradas e o atual sistema rodoviário francês teve início no seu Império.

$\mathrm{Na}$ Inglaterra, Telford e Mac Adam iniciaram a utilização de pedra marroada e pedra britada na construção de estradas de rodagem e Londres recebia os primeiros pavimentos asfálticos.

- Fase III (1838) na França começou a construção das estradas de rodagem. Surgiu, evidentemente, ao mesmo tempo, o sério problema técnicoadministrativo de coordenação correta de dois modos de transporte e de sua interação. Neste ano, na Filadélfia, os americanos pavimentaram avenidas e ruas.

- Fase IV (1858) foi inventado o britador mecânico e, em 1859, o rolo compressor com autopropulsão movido a lenha e a vapor, o que aumentou muito a utilização de brita em estradas de rodagem, pela diminuição do seu custo de produção. Assim, tem-se o inicio da pavimentação asfáltica pelo mundo, evoluindo gradativamente até a atualidade.

\section{Pavimento Flexível}

Pavimento é uma estrutura de múltiplas camadas de espessuras finitas, construída sobre

a superfície final de terraplenagem, destinada técnica e economicamente a resistir aos esforços oriundos do tráfego de veículos e do clima, e a propiciar aos usuários melhoria nas condições de rolamento com conforto, economia e segurança (BERNUCCI et al, 2008). 
Citação: Veggi E. S., Magalhães S. L. M., Analise comparativa de custos entre concreto betuminoso usinado a quente (CBUQ) e tratamento superficial duplo (TSD). E\&S - Engineering and Science, (2014), 2:1.

Segundo Souza (1980), o pavimento é uma estrutura de camadas ("layered system"), em que materiais de diferentes resistências e deformabilidades são postos em contato, resultando elevado grau de complexibilidade no que se refere ao cálculo das tensões e deformações.

Os pavimentos flexíveis são aqueles em que o revestimento é composto por uma mistura constituída, basicamente, de agregados e ligantes asfálticos. São formados por quatro a cinco camadas principais: revestimento asfáltico, base, sub-base, reforço do subleito e regularização de subleito. A Figura 3 mostra um perfil transversal típico de uma via com

pavimento flexível.

Figura 3 - Seção Transversal de Pavimento

Flexível. Fonte: BERNUCCI et al, 2008

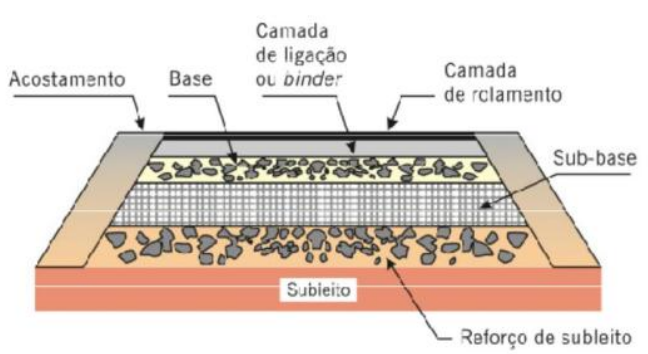

1 - Segundo Medina (1997) as principais funções do pavimento são:

Resistir e distribuir, convenientemente, ao subleito as solicitações oriundas dos veículos;

2 - Melhorar a condições de rolamento dos veículos quanto à comodidade e segurança;

3 - Resistir aos esforços horizontais que nela atuam, tornando mais durável a superfície de rolamento;

De acordo com a mesma fonte, estes foram os objetivos de melhorar as vias de terra protegendo-as das ações da água.

\section{Ligantes Asfálticos}

Os ligantes asfálticos podem ser encontrados em estado natural ou obtidos por meio da refinação. Segundo Souza (1980), são naturais quando o petróleo surge à superfície da terra, sofrendo ação do vento, que retiram os gases e óleos leves, em uma espécie de destilação natural, deixando o material asfáltico como resíduo. Os asfaltos naturais são sempre muito duros, necessitando de certa diluição para o emprego em fins rodoviários. As principais jazidas de asfaltos naturais estão em Trinidad e na Venezuela.

No Brasil, cerca de $95 \%$ das estradas pavimentadas são de revestimento asfáltico, além de ser, também, utilizado em grande parte das vias urbanas (BERNUCCI et al,2008).

Segundo Ferreira (2011), há várias razões para o uso intensivo do asfalto em pavimentação, sendo as principais:

1 - Proporciona forte união dos agregados, agindo como um ligante que permite flexibilidade controlável;

2 - É impermeabilizante, durável e resistente à ação da maioria dos ácidos, dos

álcalis e dos sais, podendo ser utilizado aquecido ou emulsionado, em amplas combinações de esqueleto mineral, com ou sem aditivos.

De acordo com Bernucci et al (2008), outras definições e conceitos de largo emprego em concreto asfáltico são difundidas. As seguintes definições e conceituações mais empregadas com referência ao material são:

1 - Betume: comumente é definido como uma mistura de hidrocarbonetos

solúvel no bissulfeto de carbono;

2 - Asfalto: mistura de hidrocarbonetos derivados do petróleo de forma natural ou por destilação, cujo principal componente é o betume, podendo, ainda, conter outros materiais 
como oxigênio, nitrogênio e enxofre em pequena proporção;

3 - Alcatrão: designação genérica de um produto que contém hidrocarbonetos, o qual é obtido por meio da queima ou destilação destrutiva do carvão, madeira, etc.

Como se pode observar nessas definições, o asfalto e alcatrão são materiais betuminosos, porque contêm betume, mas não podem ser confundidos porque suas propriedades são bastante diferentes (FERREIRA, 2011).

\section{Agregados}

O termo agregado é como material sem volume definidos, geralmente inerte de dimensões e propriedades adequadas. Define-se agregado como sendo uma mistura de pedregulho, areia, pedra britada, escoria ou outros materiais minerais (MEDINA, 1997).

Segundo a mesma fonte, os agregados naturais são compostos por diferentes minerais com composições variáveis. Mesmo com agregados de mineralogia uniforme, suas

propriedades podem ser alteradas pela oxidação, hidratação, lixiviação ou intemperismo.

Agregados artificiais são resíduos de processos industriais como: escoria de alto forno e de aciaria ou fabricados especificamente com 0 objetivo de alto desempenho, como a argila calcinada e a argila expandida (CABRAL, 2005 apud BERNUCCI 2008).

Agregados reciclados são provenientes de diversos materiais de reuso. A reciclagem de revestimentos asfálticos e resíduos de construção vêm crescendo significativamente para a formação de materiais. Em alguns países, já é fonte principal de agregados (BALBO, 2007), os agregados têm a divisão em três grupos macros, que é diferenciado quanto à granulometria. São os: graúdo (material com dimensões maiores que $2 \mathrm{~mm}$ ), miúdo (material com dimensões maiores que $0,075 \mathrm{~mm}$ e menores que $2 \mathrm{~mm}$ ) e fíler (material no qual pelo menos $65 \%$ das partículas é menor que $0,075 \mathrm{~mm}$ ). Constitui-se em principal fonte de material para formação dos solos e para formação da estrutura dos revestimentos flexíveis. São diferenciados, também, pelas formas geométricas sendo as mais comuns: lamelares (formatos de lâminas) ou cúbicas (formato mais simétrico). Usualmente, os agregados utilizados em pavimentação são de origem natural e são obtidos por processos convencionais de desmonte, escavação, britagem e dragagem em depósitos continentais, marinhos, estuários e rios.

Solos

Os solos granulares são classificados em sete grupos, variando conforme a granulometria de cada tipo de solo e de intervalos de variação dos limites da consistência do índice de grupo (DNIT, 2005).

Para diferenciar a classificação e qualidade dos solos, Pinto \& Preussler (2010) relata sobre índice de grupo (IG), que é o parâmetro que varia entre os números inteiros de 0 a 20. $\mathrm{IG}=0$ representam solos ótimos, os quais, normalmente, são utilizados para bases e sub-bases. $\mathrm{IG}=20$ representam solos péssimos, que, em regra, necessitam de estabilização granulométrica ou química. A determinação desse índice baseia-se em limites de liquidez (LL) e de plasticidade (LP) do solo e da porcentagem de material que passa na peneira de número $200(0,075 \mathrm{~mm})$. Seu valor é obtido através da seguinte expressão:

$I G=0,2 \times a+0,005 \times a \times c+0,01 \times$ b $\times d$ 
Citação: Veggi E. S., Magalhães S. L. M., Analise comparativa de custos entre concreto betuminoso usinado a quente (CBUQ) e tratamento superficial duplo (TSD). E\&S - Engineering and Science, (2014), 2:1.

Onde:

$\mathrm{a}=$ porcentagem do solo que passa na peneira $\mathrm{n}^{\circ} 200$ menos $35 \%$. $\mathrm{b}=$ porcentagem do solo que passa na peneira $\mathrm{n}^{\circ} 200$ menos $15 \%$. $\mathrm{c}=$ valor do limite de liquidez menos $40 \%$. $10 \%$.
De acordo com a Tabela 1, os solos se dividem em dois grupos: solos grossos (quando a percentagem de material que passa na peneira $n^{\circ} 200$ é inferior a $35 \%$ ) e solos finos (quando a percentagem de material que passa na peneira $n^{\circ} 200$ é superior a 35\%). A classificação é feita da esquerda para a direita do solo apresentado (DNIT, 2005).

\begin{tabular}{|c|c|c|c|c|c|c|c|c|c|c|c|}
\hline \multicolumn{12}{|c|}{ Classificação de solos } \\
\hline $\begin{array}{c}\text { Classificação } \\
\text { Geral }\end{array}$ & \multicolumn{7}{|c|}{$\begin{array}{l}\text { Materiais Granulares } 35 \% \text { (ou menos) } \\
\text { passando na peneira } n^{\circ} 200\end{array}$} & \multicolumn{4}{|c|}{$\begin{array}{l}\text { Materiais Silto-Argiloso } \\
\text { mais } 35 \% \text { passado na } \\
\text { peneira } n^{\circ} 200\end{array}$} \\
\hline Classificação & A & -1 & A-3 & & & -2 & & A-4 & A-5 & A-6 & A-7 \\
\hline em Grupos & $\begin{array}{c}\text { A-1- } \\
\text { A }\end{array}$ & $\mid \begin{array}{c}A-1- \\
B\end{array}$ & & $\begin{array}{c}\text { A-2- } \\
4\end{array}$ & A-2-5 & A-2-6 & A-2-7 & & & & $\begin{array}{l}\text { A-7-5 } \\
\text { A-7-6 }\end{array}$ \\
\hline $\begin{array}{c}\text { Granulometria - } \\
\% \text { passada na } \\
\text { peneira }\end{array}$ & \multirow{4}{*}{$\begin{array}{c}50 \\
\text { máx } \\
30 \\
\text { máx } \\
15 \\
\text { máx }\end{array}$} & \multirow{4}{*}{$\begin{array}{c}50 \\
\text { máx } \\
25 \\
\text { máx }\end{array}$} & \multirow{4}{*}{$\begin{array}{l}51 \\
\text { máx } \\
10 \\
\text { máx }\end{array}$} & \multirow[b]{4}{*}{$\begin{array}{l}35 \\
\text { máx }\end{array}$} & \multirow[b]{4}{*}{$\begin{array}{l}35 \\
\text { máx }\end{array}$} & \multirow[b]{4}{*}{ máx } & \multirow[b]{4}{*}{$\begin{array}{l}35 \\
\text { máx }\end{array}$} & \multirow[b]{4}{*}{$\begin{array}{l}36 \\
\min \end{array}$} & \multirow[b]{4}{*}{$\begin{array}{l}36 \\
\min \end{array}$} & \multirow[b]{4}{*}{$\begin{array}{l}36 \\
\min \end{array}$} & \multirow[b]{4}{*}{$\begin{array}{l}36 \\
\min \end{array}$} \\
\hline$n^{\circ} 10$ & & & & & & & & & & & \\
\hline$n^{\circ} 40$ & & & & & & & & & & & \\
\hline & & & & & & & & & & & \\
\hline $\begin{array}{l}\text { Característica } \\
\text { da fração } \\
\text { passada na } \\
\text { peneira } n^{\circ} 40\end{array}$ & \multirow[b]{3}{*}{$\begin{array}{c}6 \\
\text { máx }\end{array}$} & \multirow[b]{3}{*}{$\begin{array}{l}6 \\
\text { máx }\end{array}$} & \multirow[b]{3}{*}{ NP } & \multirow{3}{*}{$\begin{array}{l}40 \\
\text { máx } \\
10 \\
\text { máx }\end{array}$} & \multirow{3}{*}{$\begin{array}{c}41 \\
\text { máx } \\
10 \\
\text { máx }\end{array}$} & \multirow{3}{*}{$\begin{array}{c}40 \\
\text { máx } \\
11 \\
\text { máx }\end{array}$} & \multirow{3}{*}{$\begin{array}{c}41 \\
\text { máx } \\
11 \\
\text { máx }\end{array}$} & \multirow{4}{*}{$\begin{array}{c}40 \\
\text { máx } \\
10 \\
\text { máx } \\
8 \text { máx }\end{array}$} & \multirow{4}{*}{$\begin{array}{c}41 \\
\text { máx } \\
10 \\
\text { máx } \\
12 \\
\text { máx }\end{array}$} & \multirow{4}{*}{$\begin{array}{c}40 \\
\text { máx } \\
11 \\
\text { máx } \\
16 \\
\text { máx }\end{array}$} & \multirow{3}{*}{$\begin{array}{c}41 \\
\text { máx } \\
11 \\
\text { máx }\end{array}$} \\
\hline $\begin{array}{l}\text { Limite de } \\
\text { liquidez }\end{array}$ & & & & & & & & & & & \\
\hline $\begin{array}{l}\text { Indice de } \\
\text { plasticidade }\end{array}$ & & & & & & & & & & & \\
\hline Indice de grupo & 0 & 0 & 0 & 0 & 0 & 4 máx & 4 máx & & & & $\begin{array}{l}20 \\
\text { máx }\end{array}$ \\
\hline $\begin{array}{l}\text { Materiais } \\
\text { constituintes }\end{array}$ & \multicolumn{3}{|c|}{$\begin{array}{l}\text { Fragmentos de } \\
\text { pedra, } \\
\text { pedregulho fino e } \\
\text { areia }\end{array}$} & \multicolumn{4}{|c|}{$\begin{array}{l}\text { Pedregulho ou areias } \\
\text { siltosos ou agilosos }\end{array}$} & \multicolumn{2}{|c|}{ Solos siltosos } & \multicolumn{2}{|c|}{$\begin{array}{l}\text { Solos } \\
\text { argilosos }\end{array}$} \\
\hline $\begin{array}{l}\text { Comportamento } \\
\text { como subleito }\end{array}$ & \multicolumn{7}{|c|}{ Excelente a bom } & \multicolumn{4}{|c|}{ Sofrível a mau } \\
\hline
\end{tabular}

Fonte: DNIT, 2005

Tabela 1 - Classificação de solos

A Figura 4 mostra o tipo de material utilizado de acordo com os elementos de desenvolvimento do pavimento. 
Citação: Veggi E. S., Magalhães S. L. M., Analise comparativa de custos entre concreto betuminoso usinado a quente (CBUQ) e tratamento superficial duplo (TSD). E\&S - Engineering and Science, (2014), 2:1.

Figura 4 - Aplicação para execução de base e sub-base. Fonte: DNIT, 2005.

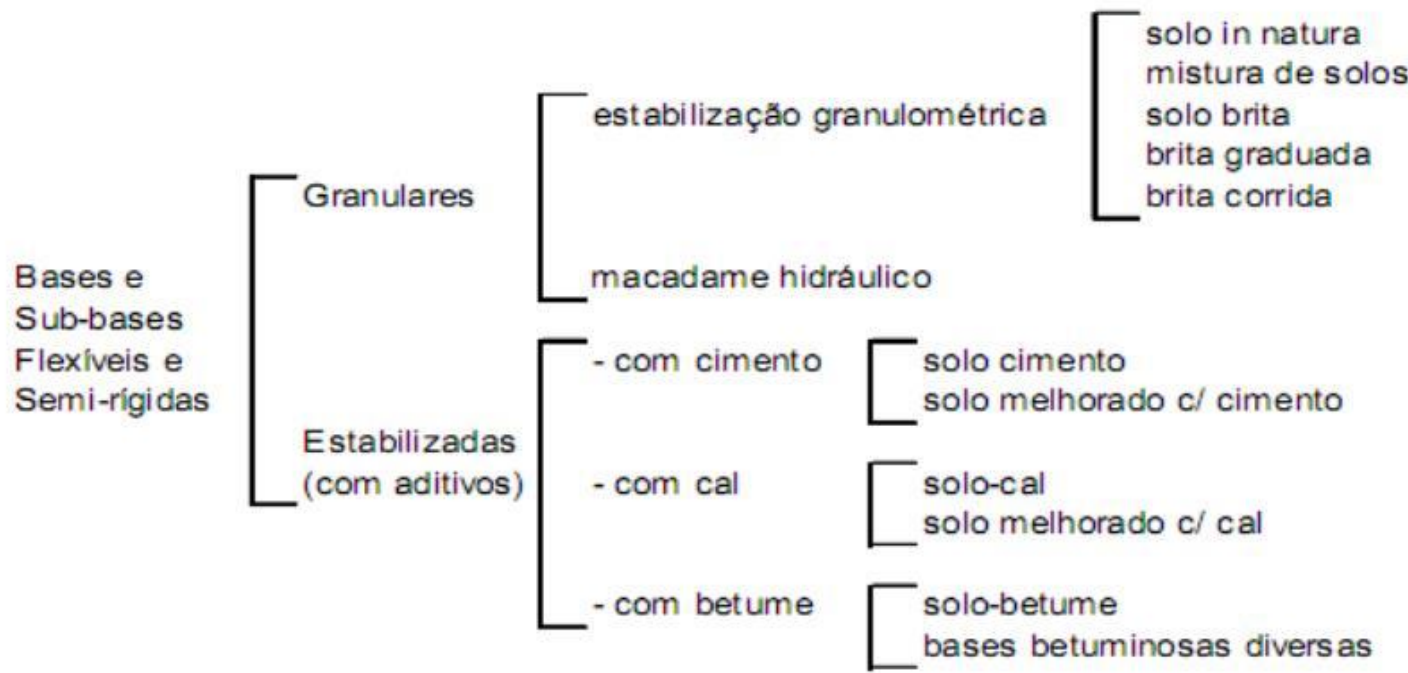

\section{Estabilização Granulométrica}

Para o aproveitamento de um solo de características ruins ou indesejáveis para uso na pavimentação, faz-se com que haja essa melhoria do solo empregando misturas de agregados para atingir as características desejáveis. Este processo sendo chamado de estabilização granulométrica (BALBO, 2007).

Processo de melhoria da capacidade resistente de materiais 'in natura" ou mistura de materiais, mediante emprego de energia de compactação adequada, de forma a se obter um produto final com propriedades adequadas de estabilidade e durabilidade (DNIT, 2010a)

O tipo de mistura e agregado a ser utilizado depende das características

\section{Revestimentos Asfálticos}

De acordo com Medina (1997), é a camada, tanto quanto possível, impermeável que recebe, diretamente, a ação do rolamento dos veículos e destinada à econômica e simultaneamente:

1 - A melhorar as condições do dos solos locais, por exemplo; as misturas de agregados podem ser realizadas para combater o cisalhamento nas camadas de reforço de subleito provenientes de solos laterítico (solos de regiões tropicais). Para solos não lateríticos é vantajoso que prevaleçam as características dos agregados utilizados (BALBO, 2007).

Para a dosagem de material destinado à estabilização, os critérios tradicionais de dosagem limitam a $25 \%$ dos solos na mistura, implicando que não sejam econômicos alguns destes procedimentos.

Para a execução deste procedimento têm-se duas opções: fazer a mistura em um misturador de agregados ou misturar com equipamentos e maquinários "in loco".

rolamento quanto à comodidade $\mathrm{e}$ segurança;

2 - A resistir aos esforços horizontais que nele atuam, tornando mais durável a superfície de rolamento;

A Figura 5 mostra os tipos de revestimentos existentes: 
Citação: Veggi E. S., Magalhães S. L. M., Analise comparativa de custos entre concreto betuminoso usinado a quente (CBUQ) e tratamento superficial duplo (TSD). E\&S - Engineering and Science, (2014), 2:1.

Figura 5 - Fluxograma de orientação para revestimento. Fonte: DNIT, 2005.

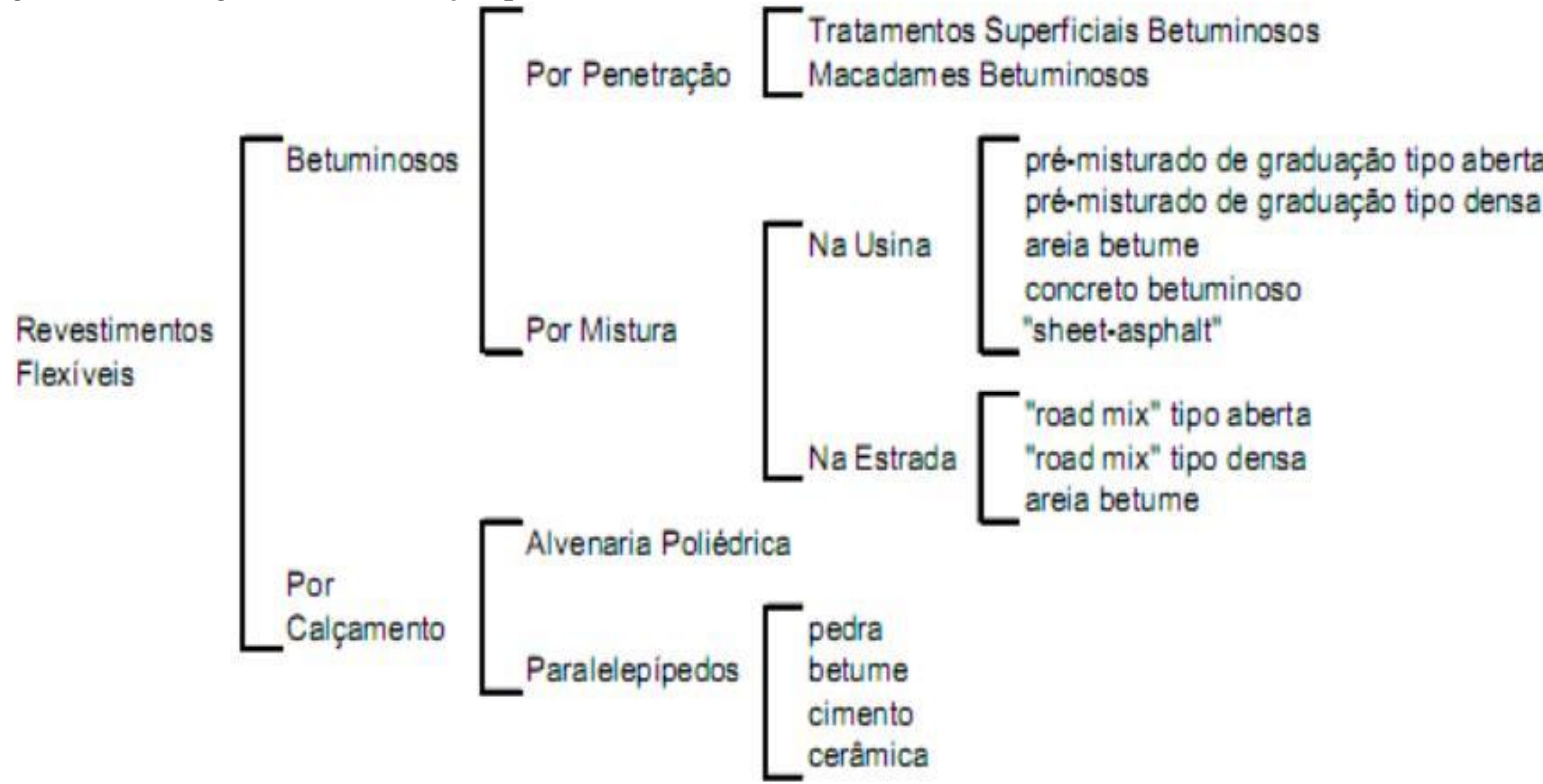

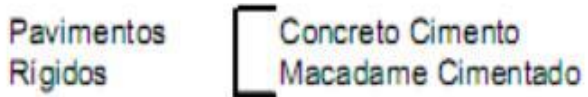

\section{Tratamento Superficial Duplo}

Os chamados tratamentos superficiais duplos consistem em aplicação de ligantes asfálticos e agregados sem mistura prévia, na pista, com posterior compactação que promove o recobrimento parcial e a adesão entre agregados e ligantes (BERNUCCI, et al, 2008).

As principais funções do tratamento superficial duplo são:

1-Impermeabilizar a infra-estrutura do pavimento.

2-Proporcionar um revestimento antiderrapante.

3- Proporcionar um revestimento de alta elasticidade para acompanhar deformações das camadas inferiores.
Figura 6 - Esquema de tratamento superficial Duplo. Fonte: Nascimento, 2004 apud Bernucci et al, 2008 .
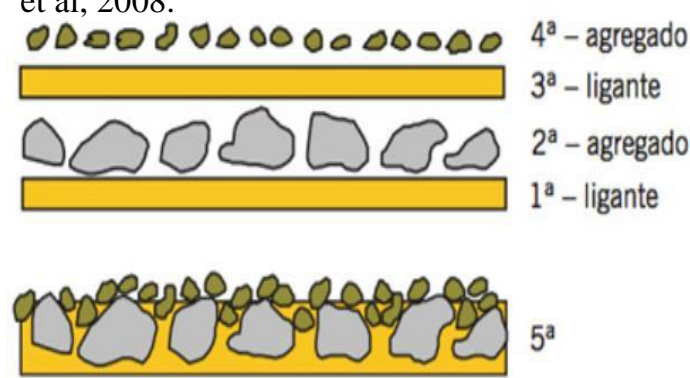

A sua pequena espessura não corrige grandes irregularidades, transversalmente ou longitudinalmente (BALBO, 2007).

O tratamento superficial duplo (TSD) consiste em um tipo de revestimento que é executado na pista, em camadas de agregados e ligantes asfálticos:

1 - Aplicação do ligante asfáltico: sobre a base imprimada, curada e isenta de material solto, aplica-se um banho de ligante com carro-tanque provido de barra espargidora; 
Citação: Veggi E. S., Magalhães S. L. M., Analise comparativa de custos entre concreto betuminoso usinado a quente (CBUQ) e tratamento superficial duplo (TSD). E\&S - Engineering and Science, (2014), 2:1.

2 - Espalhamento do agregado: após a aplicação do ligante, efetua-se $o$ espalhamento do agregado, de preferência com caminhões basculantes dotados de dispositivos distribuidores;

O termo penetração direta foi introduzido para melhor identificar os tratamentos superficiais, nos quais é necessário iniciar-se por um espalhamento de agregado. Nesse tipo de tratamento era prevista uma penetração (agulhamento) ignificativa do agregado no ligante já durante a compressão. A viscosidade para a capa selante deve ser alta e o primeiro agregado distribuído deve
3 - Compactação: após o espalhamento do agregado, é iniciada a compressão do mesmo sobre o ligante, com rolo liso ou pneumático. Estes procedimentos estão ilustrados na Figura 6.

possuir $25 \mathrm{~mm}$ para penetração (BERNUCCI et al, 2008).

Para os tratamentos superficiais o uso de ligantes de rupturas rápidas é o mais utilizado, porém depende de cada região, climas e de serviço podendo intercalar com os de ruptura média ou ruptura lenta. A Tabela 2 que tem como origem a resolução da Agência Nacional do Petróleo - ANP (2013) demonstra sobre esses ligantes.

\begin{tabular}{|c|c|c|c|c|c|c|c|}
\hline \multirow[t]{3}{*}{ Característica } & \multirow[t]{3}{*}{ Unidade } & \multicolumn{4}{|c|}{ Limite } & \multicolumn{2}{|c|}{ Método (1) } \\
\hline & & \multicolumn{2}{|c|}{ Ruptura Rápida } & \multicolumn{2}{|c|}{ Ruptura Média } & \multicolumn{2}{|c|}{ ABNT ASTM } \\
\hline & & RR-1C & RR-2C & RM-1C & $\begin{array}{l}\text { RM- } \\
2 \mathrm{C}\end{array}$ & & \\
\hline \multicolumn{8}{|c|}{ Ensaio para a emulsão } \\
\hline $\begin{array}{l}\text { Viscosidade Saybolt Furol } \\
\text { a } 25^{\circ} \mathrm{C} \text { máx. }\end{array}$ & s & 90 & - & - & - & 14491 & D244 \\
\hline $\begin{array}{l}\text { Viscosidade Saybolt Furol } \\
\text { a } 50^{\circ} \mathrm{C}\end{array}$ & s & - & $\begin{array}{l}100 \mathrm{a} \\
400\end{array}$ & $\begin{array}{l}20 a \\
200\end{array}$ & $\begin{array}{l}100 \mathrm{a} \\
400\end{array}$ & 14491 & D244 \\
\hline Sedimentação, máx. & $\% \mathrm{~m} / \mathrm{m}$ & 5 & 5 & 5 & 5 & 6570 & D6930 \\
\hline $\begin{array}{l}\text { Peneiração }(0,84 \mathrm{~mm}) \text {, } \\
\text { máx. }\end{array}$ & $\% \mathrm{~m} / \mathrm{m}$ & 0,1 & 0,1 & 0,1 & 0,1 & 14393 & D6933 \\
\hline $\begin{array}{l}\text { Resistência à água } \\
\text { (cobertura), mín. (2) }\end{array}$ & $\%$ & 80 & 80 & 80 & 80 & 14249 & D244 \\
\hline $\begin{array}{l}\text { Adesividade em agregado } \\
\text { miúdo, mín. }\end{array}$ & $\%$ & - & - & - & - & $\begin{array}{l}14757 \\
(3)\end{array}$ & - \\
\hline Carga da partícula & - & positiva & positiva & positiva & $\begin{array}{l}\text { positi } \\
\text { va }\end{array}$ & 6567 & D244 \\
\hline pH, máx. & - & - & - & - & - & 6299 & - \\
\hline \multicolumn{8}{|l|}{ Destilação } \\
\hline Solvente destilado & $\% \mathrm{v} / \mathrm{v}$ & - & - & 0 a 12 & 0 a 12 & 6568 & D244 \\
\hline Resíduo seco, mín. & $\% \mathrm{~m} / \mathrm{m}$ & 62 & 67 & 62 & 65 & 14376 & D6934 \\
\hline \multicolumn{8}{|l|}{ Desemulsibilidade } \\
\hline Mín. & \multirow{2}{*}{$\% \mathrm{~m} / \mathrm{m}$} & 50 & 50 & - & - & \multirow{2}{*}{6569} & \multirow{2}{*}{ D6936 } \\
\hline Máx. & & - & 50 & 50 & - & & \\
\hline Mistura com fíler silício & $\%$ & - & - & - & - & 6302 & D244 \\
\hline Mistura com cimento & $\%$ & - & - & - & - & 6297 & D244 \\
\hline \multicolumn{8}{|c|}{ Ensaio para o resíduo da emulsão obtido pela NBR 14896} \\
\hline $\begin{array}{l}\text { Penetração a } 25^{\circ} \mathrm{C}(100 \mathrm{~g} \\
\text { e } 5 \mathrm{~s})\end{array}$ & $\mathrm{mm}$ & $\begin{array}{l}4,0 \text { a } \\
15,0\end{array}$ & $\begin{array}{l}4,0 \mathrm{a} \\
15,0\end{array}$ & $\begin{array}{l}4,0 \mathrm{a} \\
15,0\end{array}$ & $\begin{array}{l}4,0 \mathrm{a} \\
15,0\end{array}$ & 6576 & D5 \\
\hline $\begin{array}{l}\text { Teor de betume, mín. } \\
\text { Ductilidade a } 25^{\circ} \mathrm{C} \text {, mín. }\end{array}$ & $\begin{array}{l}\% \\
\mathrm{~cm}\end{array}$ & $\begin{array}{l}97 \\
40\end{array}$ & $\begin{array}{l}97 \\
40\end{array}$ & $\begin{array}{l}97 \\
40\end{array}$ & $\begin{array}{l}97 \\
40\end{array}$ & $\begin{array}{l}14855 \\
6293\end{array}$ & $\begin{array}{l}\text { D2042 } \\
\text { D113 }\end{array}$ \\
\hline
\end{tabular}

Fonte: ANP, 2013

Tabela 2 - Características de ligantes de ruptura rápida e média 
Citação: Veggi E. S., Magalhães S. L. M., Analise comparativa de custos entre concreto betuminoso usinado a quente (CBUQ) e tratamento superficial duplo (TSD). E\&S - Engineering and Science, (2014), 2:1.

Concreto Betuminoso Usinado a Quente (Cbuq)

O CBUQ é uma mistura executada a quente, sendo composta de agregados graúdos, miúdos e material de enchimento (fíler), caso necessário, mais o cimento asfático (CAP) (BALBO, 2007).

Pode ser utilizado como camada de regularização (binder), base, regularização ou reforço de pavimento. É mais usual como revestimento asfáltico.

O CBUQ segundo Bernucci et al, (2008) possui 4 tipos diferentes de granulometria de dosagem, de acordo com a graduação dos agregados e fíler: densa, aberta, uniforme e com degrau ou descontinua.

1- Densa: Curva granulométrica continua próximo a densidade máxima. 2 - Uniforme:Curva granulométrica íngreme pela pouca variação da estrutura mineral.

3 - Aberta: Curva granulométrica continua nos agregados de maior diâmetro porém, pouco fíler que é fundamental para preencher vazios.

4 - Descontinua: Curva granulométrica descontínua não apresenta agregados de tamanhos intermediários.

\section{Como mostra no Gráfico 1:}

Gráfico 1 - Curvas granulométricas dos tipos de CBUQ. Fonte: Bernucci et al. 2008.

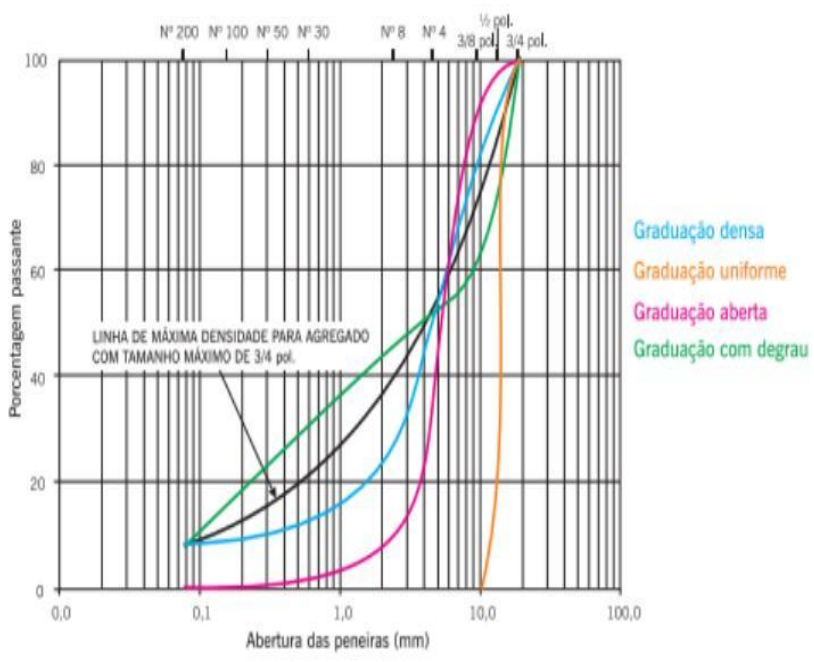

E\&S - Engineering and Science ISSN: 2358-5390
Os critérios de dosagem de misturas asfálticas não são únicos, dependem do tipo de CBUQ necessário para determinada localidade e como é feito usualmente por essas. A dosagem de CBUQ tem como objetivo obter e resultar: mistura adequadamente trabalhável, mistura estável sobre ações de cargas estáticas ou móveis, mistura durável com teor de asfalto adequado, baixa deformação permanente, mistura pouco suscetível à fissuração por fadiga e possuir vazios suficientes e não excessivos.

Os traços utilizados para fabricação de CBUQ serão definidos a partir de sua porcentagem de cada material e de suas massas específicas reais, para uma massa unitária igual a 100. O peso específico aparente faz-se a relação com a massa total do CBUQ sobre o volume de agregados e ligantes utilizados, demonstrado pela seguinte equação:

\section{$\mathrm{ymax}=\mathrm{mt} / \mathrm{Vag}+\mathrm{Vam}+\mathrm{Vf}+\mathrm{Vb}$}

Onde:

Vag - Volume de agregado graúdo Vam - Volume de agregado miúdo Vf - Volume de fíler $\mathrm{Vb}$ - Volume de asfalto

Segundo Balbo (2007), a densidade aparente tem um valor médio de $2,5 \mathrm{~g} / \mathrm{cm}$ produção, os agregados deverão ser corretamente dosados por meio de unidades de classificação, devendo estar perfeitamente secos, o que é garantido pelo tambor de aquecimento na produção. Além da secagem completa por contato do agregado com a chama do queimador, sua temperatura é elevada a um valor compatível (cerca de $175^{\circ} \mathrm{C}$ ) com aquele de usinagem do CAP, para que não ocasione a queda de temperatura da mistura final, que deverá chegar à pista para aplicação próximo de $140^{\circ} \mathrm{C}$ a $145^{\circ} \mathrm{C}$. 
Citação: Veggi E. S., Magalhães S. L. M., Analise comparativa de custos entre concreto betuminoso usinado a quente (CBUQ) e tratamento superficial duplo (TSD). E\&S - Engineering and Science, (2014), 2:1.

O CAP é um material termossensível utilizado para a fabricação do CBUQ em trabalhos de pavimentação, pois, além de suas propriedades aglutinantes e impermeabilizantes, possui características de flexibilidade e alta resistência. Em suas aplicações, o CAP deve ser homogêneo e estar livre de água para que sua utilização seja adequada, pela norma do DNIT (2006) como: o CAP 30/45, CAP 50/70 e CAP 85/100, a Tabela 3 mostra as características técnicas desse material.

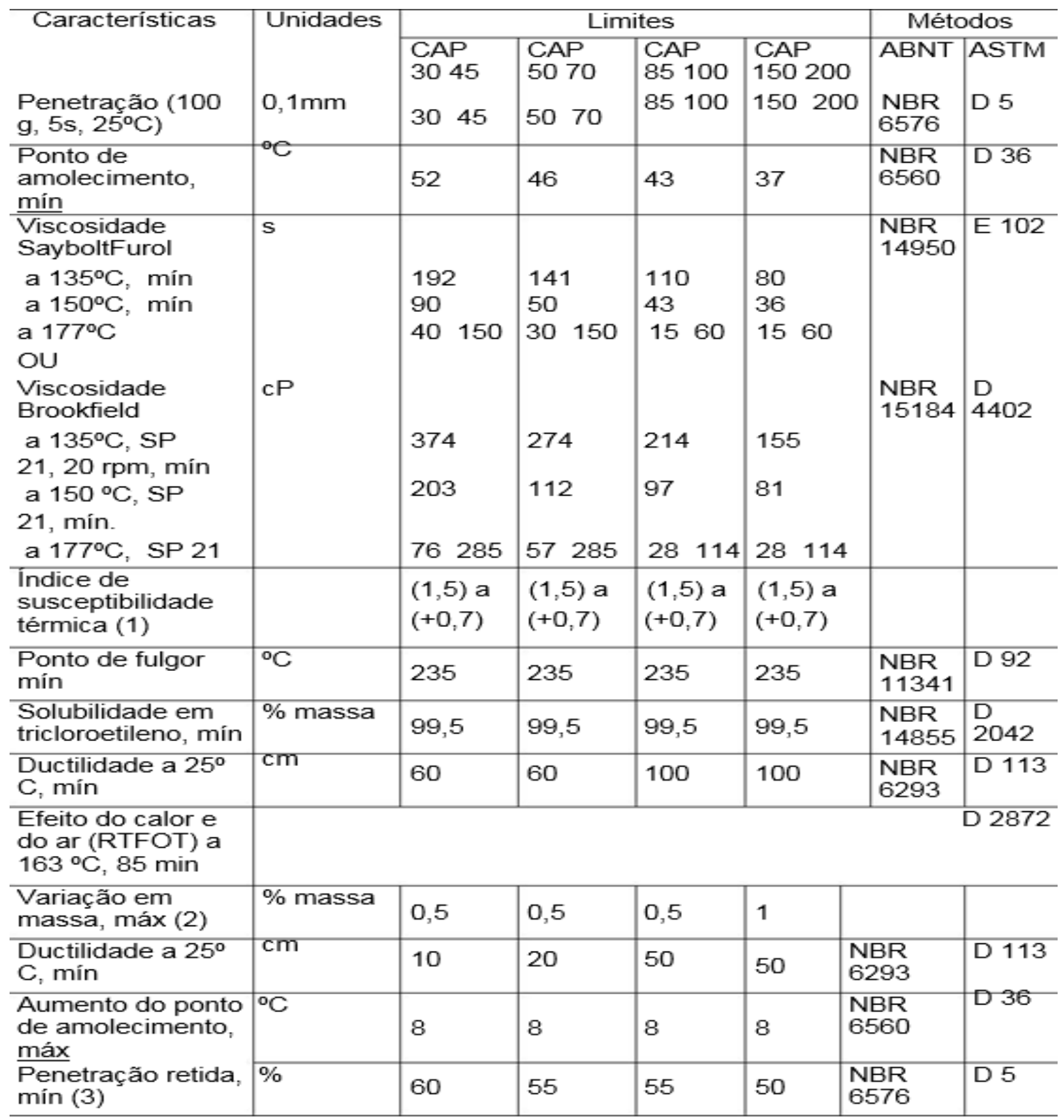

Fonte: ANP, 2013

Tabela 3 - Características dos CAP

Pode-se dizer que a dosagem de uma mistura asfáltica constitui um processo de formulação no qual 
Citação: Veggi E. S., Magalhães S. L. M., Analise comparativa de custos entre concreto betuminoso usinado a quente (CBUQ) e tratamento superficial duplo (TSD). E\&S - Engineering and Science, (2014), 2:1.

se busca uma composição granulométrica de agregados com naturezas específicas e de uma adição de CAP, de tal sorte que, após mistura à temperatura adequada e subseqüente compactação, adequadas para suportar cargas que solicitam um dado pavimento, consideradas as condições climáticas locais, a posição relativa da mistura da estrutura de pavimento, esse material não deverá apresenta deterioração precoce.

Quando a espessura de projeto de revestimento for maior que $70 \mathrm{~mm}$ é comum fazer uma subdivisão em duas camadas para fins de execução; a superior que fica em contato com os pneus dos veículos é chamada de camada de rolamento ou simplesmente de

$$
\text { "capa" e tem requisitos de }
$$
vazios bastante restritos, para garantir a impermeabilidade; a camada inferior é referida como camada de ligação ou intermediária (ou ainda de binder) e pode ser projetada com um índice de vazios ligeiramente maior, com a finalidade de diminuir o teor de ligante e baratear a massa asfáltica. Esse procedimento também modificará as características mecânicas e de flexibilidade da mistura, o que deve ser levado em conta no dimensionamento do pavimento. (BERNUCCI et al, 2008)

\section{Número $N$}

Segundo o Manual de Contagem de tráfego do DNIT (2006c) número $\mathrm{N}$ de operações do eixo padrão é o número de repetições (ou operações) dos eixos dos veículos, equivalentes às solicitações do eixo padrão rodoviário de 8,2 tf durante o período considerado de vida útil do pavimento, calculado pela expressão:

\section{$\mathrm{N}=\mathrm{Vt} \times \mathrm{FV} \times \mathrm{FR}$}

onde:

Vt - volume total de veículos no período de projeto; FV - fator de veículos; FR - fator climático regional;

Volume Total de Veículos

$\mathrm{O}$ Vt é obtido através da expressão: $\mathrm{Vt}=365 \times \mathrm{VMD} \times \mathrm{P}$

Onde:

$\mathrm{P}$ - período de projeto em anos. VMD - Volume médio diário de veículos;

É calculado em função do volume médio diário (VMD) de veículos que passa na faixa da via mais solicitada. O seu valor é determinado para o ano de abertura (V1) e projetada uma taxa de crescimento para todo o período de projeto, admitindo-se, conforme SOUZA

(1980), taxas de crescimento anual em progressão geométrica (não linear) ou aritmética (linear), para o cálculo do Vt. As componentes importantes na obtenção destes parâmetros são:

1 - Volume inicial obtido com as estatísticas de tráfego existente;

2 - Tráfego desviado, correspondente ao montante de veículos que passarão a utilizar o trecho projetado após sua abertura e que atualmente utilizam rotas alternativas;

3 - Tráfego gerado, ou seja, as novas viagens que resultarão das variações no tipo e intensidade de serviços nas áreas de influência do trecho de projeto; 4 - Dados econômicos da região. 
Citação: Veggi E. S., Magalhães S. L. M., Analise comparativa de custos entre concreto betuminoso usinado a quente (CBUQ) e tratamento superficial duplo (TSD). E\&S - Engineering and Science, (2014), 2:1.

Fator de Veículos $(F v)$

A determinação do fator de veículos é feita por amostragem no tráfego, estabelecendo-se a classificação pelo número de eixos, assim agrupados, DNIT (2006c):

1 - Automóveis e utilitários;

2 - Ônibus;

3- Caminhões leves, com dois eixos simples, de rodas simples;

4 - Caminhões médios, com dois eixos, sendo o traseiro de rodas duplas;

5 - Caminhões pesados, com dois eixos, sendo o traseiro "tandem";

6 - Reboques e semi-reboques: as diferentes combinações de veículos, em unidades múltiplas.

O fator de veículo é um número que multiplicado pela quantidade de veículos em operação, resulta no número de eixos equivalentes padrão para vários tipos de veículos que compõem o tráfego. Não são considerados os fatores de veículos dos automóveis e caminhões leves. O FV é obtido em função do fator de carga (FC) e do fator de eixos (FE), pela expressão:

\section{$\mathrm{FV}=\mathrm{FC} \times \mathrm{FE}$}

Para o cálculo desses fatores é necessário que sejam colhidas informações que envolvam volume e composição de tráfego. Este procedimento possibilita a obtenção de dados básicos para os programas de planejamento, elaboração de planos diretores, estudos de viabilidade técnica e econômica e também de subsídios para o tratamento estatístico de acidentes, policiamento e pesagem. (DNIT, 2006c).

Para a determinação do fator de carga há duas maneiras de calcular, pelo método da United States Army Corps of Engineers - USACE ou pelo American Association of State Highway and Transportation Oficials - AASHTO conforme a Tabela 4 (PINTO \& PREUSSLER, 2010).

\begin{tabular}{|c|c|c|c|}
\hline Tipo de eixo & $\begin{array}{l}\text { Faixas de } \\
\text { cargas (tf) }\end{array}$ & $\begin{array}{l}\text { Equações }(P \text { em } t) \\
\text { USACE }\end{array}$ & $\begin{array}{l}\text { Equações }(P \text { em } t) \\
\text { AASHTO }\end{array}$ \\
\hline Dianteiro simples & $0-8$ & $F c=2,0782 \times 10^{-4} \times P^{4,0175}$ & $\mathrm{Fc}=(\mathrm{P} / 7,77)^{4,32}$ \\
\hline Traseiro simples & $\geq 8$ & $F_{C}=1,832 \times 10^{-6} \times P^{6.2542}$ & $\mathrm{~F}_{\mathrm{c}}=(\mathrm{P} / 8,17)^{4.32}$ \\
\hline \multirow{2}{*}{ Tandem duplo } & $0-11$ & $F_{C}=1,592 \times 10^{-4} \times P^{3,472}$ & \multirow[t]{2}{*}{$F c=(P / 15,08)^{4,14}$} \\
\hline & $\geq 11$ & $F c=1,528 \times 10_{-6} \times P_{5.484}$ & \\
\hline \multirow{2}{*}{ Tandem triplo } & $0-18$ & $F_{c}=8,0359 \times 10 \times P^{3,3549}$ & \multirow[t]{2}{*}{$F_{c}=(P / 22,95)^{4.22}$} \\
\hline & $\geq 18$ & $F_{C}=1,3229 \times 10_{-7} \times P$ & \\
\hline
\end{tabular}

Fonte: DNIT, 2006c

Tabela 4 - Fatores de equivalência de carga do USACE e AASHTO

O cálculo do fator de carga é a somatória da equivalência ou pelo método da USACE ou pelo método da AASHTO, dos tipos de eixos em porcentagem.

O fator de eixo (FE) é um valor que transforma o tráfego em número de eixos médios por veículos, em função da composição de tráfego mais solicitada, em números de passagens de eixos equivalentes. Para a determinação do $\mathrm{FE}$, calcula se $\mathrm{o}$ 
Citação: Veggi E. S., Magalhães S. L. M., Analise comparativa de custos entre concreto betuminoso usinado a quente (CBUQ) e tratamento superficial duplo (TSD). E\&S - Engineering and Science, (2014), 2:1.

número de eixos dos tipos de veículos

expressão:

atuantes na rodovia, através da

$$
\mathrm{FE}=(\mathrm{P} 2 / 100) \times 2+\ldots+(\mathrm{Pn} / 100) \times \mathrm{n}
$$

$\mathrm{P} 2=$ porcentagem de veículos de 2 eixos;

$\mathrm{Pn}=$ porcentagem de veículos de $\mathrm{n}$ eixos

$$
\mathrm{P} 2+\ldots .+\mathrm{Pn}=100 \%
$$

\section{Fator Climático Regional (Fr)}

Este fator considera as variações de umidade dos materiais dos pavimentos em todas as estações do ano, acarretando em alteração na capacidade de suporte dos mesmos. A pista experimental da AASHTO estabeleceu valores entre 0,2 (baixos teores de umidade) e 5,0 (materiais saturados) segundo Benevides (2000).

$$
\mathrm{H}_{\mathrm{m}}=77,67 \times \mathrm{N}_{0,0482} \times \mathrm{CBR}
$$

Adota-se FR $=1,0$, conforme

Souza (1980), para o dimensionamento de pavimentos flexíveis, em virtude de que não será o

\begin{tabular}{|c|c|}
\hline Componentes do pavimento & $\begin{array}{l}\text { Coeficiente } \\
\text { K }\end{array}$ \\
\hline Base ou revestimento de concreto betuminoso & 2,00 \\
\hline Base ou revestimento pré misturado a quente, de graduação densa & 1,70 \\
\hline Base ou revestimento pré misturado a frio, de graduaçäo densa & 1,40 \\
\hline Base ou revestimento betuminoso por penetração & 1,20 \\
\hline Camadas granulares & 1,00 \\
\hline Solo cimento com resistência à compressão a 7 dias, superior a $45 \mathrm{~kg} / \mathrm{cm}$ & 1,70 \\
\hline Tdem, com resistênclia a compressäo a 7 dlas, entre $45 \mathrm{~kg} / \mathrm{e} 28 \mathrm{~kg} / \mathrm{cm}$ & 1,40 \\
\hline Tdem, com resistência à compressão a 7 dlas, entre $28 \mathrm{~kg} / \mathrm{cm}$ e $21 \mathrm{~kg} / \mathrm{cm}$ & 1,20 \\
\hline
\end{tabular}
fator preponderante para o número $\mathrm{N}$.

\section{Dimensionamento}

Com a aplicação da equação da AASHTO e utilizando o CBR do subleito tem-se a espessura total do pavimento. Posteriormente utiliza o CBR da sub-base para a determinação da espessura da base. Segundo Pinto (1991), não há necessidade da camada de base e subbase ser superior a $35 \mathrm{~cm}$ devido a resiliência que o pavimento apresenta, a capacidade de se deformar e voltar a seu formato original, adota-se $o$ espessura máxima das camadas de 40 $\mathrm{cm}$ como uma medida adicional de margem de segurança para o subleito.

A equação apresentada a seguir fornece a espessura total do pavimento (Ht) em função do número $\mathrm{N}$ e do CBR.

Depois de feita a equação da espessura total do pavimento, determina-se a espessura das camadas, para a espessura do pavimento temos a seguinte Tabela 5.

\begin{tabular}{l|l}
$\mathrm{N}$ & Espessura mínima de revestimento \\
\hline $\mathrm{N} \leq 10^{8}$ & Tratamento Supericial \\
\hline $10^{8}<\mathrm{N} \leq 5 \times 10^{8}$ & CBUQ de $5 \mathrm{~cm}$ de espessura \\
\hline $5 \times 10^{8}<\mathrm{N} \leq 10$ & CBUQ de $7,5 \mathrm{~cm}$ de espessura \\
\hline $10<\mathrm{N} \leq 5 \times 10^{7}$ & CBUQ de $10,0 \mathrm{~cm}$ de espessura \\
\hline $\mathrm{N} 55 \times 10^{7}$ & CBUQ de $12,5 \mathrm{~cm}$ de espessura \\
\hline Fonte: DNIT, 20060 &
\end{tabular}

Tabela 5 - Determinação da espessura do revestimento

Determinação do coeficiente de equivalência estrutural para as camadas do pavimento está apresentada na tabela 6 a seguir: 


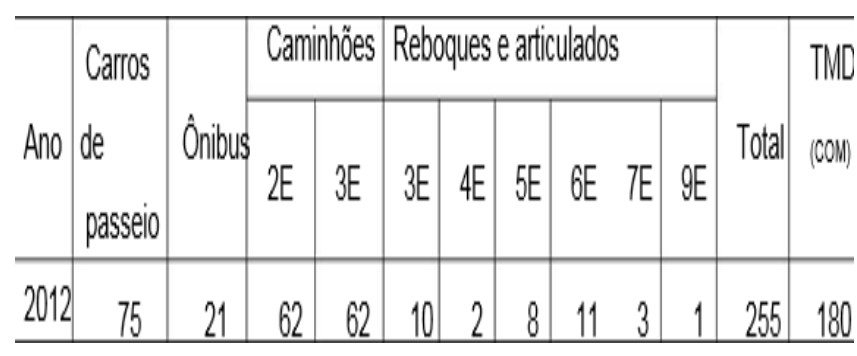

Tabela 6 - Coeficiente de equivalência

O coeficiente estrutural para a base e sub-base será $\mathrm{k}=1$. Determina-se a espessura total do pavimento.

Quando se tratar de tratamento superficial duplo desconsidera a espessura dovb revestimento para determinar as espessuras do pavimento, utiliza-se as inequações descritas abaixo e de acordo com o DNIT (2006b), nenhuma camada granular pode ser maior que 20 $\mathrm{cm}$ :

$\mathrm{R} \times \mathrm{Kr}+\mathrm{B} \times \mathrm{KB} \geq \mathrm{HSB}$

Sendo:

$\mathrm{R}$ - Espessura do revestimento; $\mathrm{Kr}$ - Coeficiente equivalente estrutural; do revestimento;

B - Espessura da base;

$\mathrm{KB}$ - Coeficiente equivalente estrutural da base;

Determina a espessura da base mais do revestimento por:

$$
\mathrm{R} \times \mathrm{Kr}+\mathrm{B} \times \mathrm{KB}+\mathrm{hSB} \times \mathrm{Ks}
$$
$\geq \mathrm{HSL}$

Sendo:

$\mathrm{R}$ - Espessura do revestimento;

$\mathrm{Kr}$ - Coeficiente equivalente estrutural do revestimento;

B - Espessura da Base;

$\mathrm{KB}$ - Coeficiente equivalente estrutural da base;

HSB - Espessura da sub-base;

$\mathrm{Ks}$ - Coeficiente equivalente estrutural da base;
HSL - Espessura da sub-base mais base e revestimento.

\section{Sistema de Gerência de Pavimentação}

O gerenciamento de rodovias vai se fundamentar na fiscalização $\mathrm{e}$ monitoração a qual se refere à inspeção periódica de condições técnicas aceitáveis, dos componentes das rodovias, para as condições de uso (DNIT, 2005).

Os materiais de construção no decorrer de sua vida de serviços apresentam processos de danificação e degradação inevitáveis, com o decorrer do tempo perdendo assim suas propriedades mecânicas (BALBO, 2007). Para o gerenciamento pelo Manual de Conservação do DNIT (2005) tem-se as seguintes monitorações cujo englobam materiais e serviços:

\section{1 - Pavimentos}

2 - Obras de arte especiais

3 - Elementos de proteção e segurança

4 - (Barreiras, sinalização e iluminação)

5 - Terraplenos e estrutura de contenção

6 - Drenagem e obras de arte correntes

7-Acesso, trevos, intercessões, retornos, acostamentos e canteiro central.

8 - Faixa de domínio e áreas lindeiras

Componentes estruturais destes itens os defeitos mais recorrentes se encontram nos pavimentos. Para uma explicação técnica de fissuras no pavimento, não se tem ao certo as causas, nem mesmo a combinação de vários fatores. As primeiras patologias visíveis e que causam manutenção são as fissuras, ao longo de vida do pavimento outros danos apareceram, originadas de outros fatores (BALBO, 2007).

\section{Incidências de Custos em Pavimentação}

Incidências de custos em pavimentação são as análises de diferentes formas para execução de revestimento ao decorrer da vida 
Citação: Veggi E. S., Magalhães S. L. M., Analise comparativa de custos entre concreto betuminoso usinado a quente (CBUQ) e tratamento superficial duplo (TSD). E\&S - Engineering and Science, (2014), 2:1.

útil, conservando-o e mantendo em condições de rodagem com segurança.

Para comparar custo dos revestimentos flexíveis o Manual de Conservação do DNIT (2005), leva em consideração campanhas de manutenção (anual) e conservação (período de vida útil do revestimento), admite-se para campanha de manutenção leve o período de 5 anos para CBUQ e 2 anos para TSD e para campanha de manutenção pesada o período de 10 anos para o CBUQ e 5 para o TSD.

A seguir, expõem-se os prováveis defeitos encontrados em revestimentos asfálticos e orientações de como restaurá-los.

\section{Coleta de Dados}

Realizou-se da seguinte maneira a coleta de dados:

a) Pesquisa bibliográfica em livros, teses, artigos, normas sobre pavimentação, camadas granulares, revestimentos e custos de pavimentação.

b) Pesquisa documental nos custos médios gerenciais, que é elaborado pelo DNIT;

\section{Dimensionamento do Pavimento}

Fez-se o dimensionamento das camadas do pavimento utilizando os seguintes métodos:

1 - do número equivalente de operação de eixo padrão $(\mathrm{N})$ inicial $\mathrm{O}$ VMD feito a partir da contagem de tráfego dos veículos comerciais (excluindo carros de passeio) dos dois lados da via, a amostra utilizada para que atenda este trabalho é como já descrita.

Realizou uma contagem simulada de tráfego para um período de 24 horas para a determinação do
VMD, havendo as seguintes considerações:

1-O tráfego foi obtido em amostras aleatórias

2 - Desconsiderar desvios de tráfegos;

3-Não se pode afirmar características econômicas que influenciam no tráfego por ser simulado;

Feita essas considerações obteve estes números:

O VMD = 180/2 = 90; sendo que $63,6 \%$ são de caminhões.

$\mathrm{O} \mathrm{Vt}=90 \times 365$ (dias do ano) $\mathrm{x}$ $1($ período em ano $)=32.850$

Para o calculo de fator de veículo (FV), neste trabalho é necessário a utilização do método desenvolvido pela USACE para o fator de carga, pois majora as cargas fazendo com que o valor do número $\mathrm{N}$ atinja a

\begin{tabular}{l|l|l|l|l}
\hline Categorias & $\%$ & FE & FC (USACE) & FV \\
\hline Veículos 2 eixos & $53,73 \%$ & 1,075 & 0,211 & - \\
\hline Veículos 3 eixos & $36,47 \%$ & 1,094 & 0,246 & - \\
\hline Veículos 4 eixos & $0,78 \%$ & 0,031 & 0,506 & - \\
\hline Veículos 5 eixos & $3,14 \%$ & 0,157 & 0,316 & - \\
\hline Veículos 6 eixos & $4,31 \%$ & 0,259 & 0,492 & - \\
Veículos 7 eixos & $1,18 \%$ & 0,082 & 0,207 & - \\
\hline Veículos 9 eixos & $0,39 \%$ & 0,035 & 0,216 & - \\
\hline Total & 100,00 & 2,733 & 2,194 & 5,99 \\
\hline
\end{tabular}

Fator de veículo $=5,99$

margem desejada.

Fator de eixo na tabela 7:

Tabela 7 - Fator de eixo X fator de carga $=$ Fator de veículo

Fator de veículo $=5,99$

O fator regional climático é de 
Citação: Veggi E. S., Magalhães S. L. M., Analise comparativa de custos entre concreto betuminoso usinado a quente (CBUQ) e tratamento superficial duplo (TSD). E\&S - Engineering and Science, (2014), 2:1.

$\mathrm{O}$ número $\mathrm{N}$ inicial para $\mathrm{O}$ dimensionamento é: Ninicial $=32.850 \times 5,99 \times 1,00=1,97$ E+05.

\begin{tabular}{l|l|l|l}
\hline Ano & Numero $N$ & $(\mathrm{t})$ & N Acumulado \\
\hline 2012 & $2,03 \mathrm{E}+05$ & $3 \%$ & $2,03 \mathrm{E}+05$ \\
\hline 2013 & $2,09 \mathrm{E}+05$ & $3 \%$ & $4,12 \mathrm{E}+05$ \\
\hline 2014 & $2,15 \mathrm{E}+05$ & $3 \%$ & $6,27 \mathrm{E}+05$ \\
\hline 2015 & $2,22 \mathrm{E}+05$ & $3 \%$ & $8,49 \mathrm{E}+05$ \\
\hline 2016 & $2,28 \mathrm{E}+05$ & $3 \%$ & $1,08 \mathrm{E}+06$ \\
\hline 2017 & $2,35 \mathrm{E}+05$ & $3 \%$ & $1,31 \mathrm{E}+06$ \\
\hline 2018 & $2,42 \mathrm{E}+05$ & $3 \%$ & $1,55 \mathrm{E}+06$ \\
\hline 2019 & $2,50 \mathrm{E}+05$ & $3 \%$ & $1,80 \mathrm{E}+06$ \\
\hline 2020 & $2,57 \mathrm{E}+05$ & $3 \%$ & $2,06 \mathrm{E}+06$ \\
\hline 2021 & $2,65 \mathrm{E}+05$ & $3 \%$ & $2,33 \mathrm{E}+06$ \\
\hline 2022 & $2,73 \mathrm{E}+05$ & $3 \%$ & $2,60 \mathrm{E}+06$ \\
\hline 2023 & $2,81 \mathrm{E}+05$ & $3 \%$ & $2,88 \mathrm{E}+06$ \\
\hline 2024 & $2,89 \mathrm{E}+05$ & $3 \%$ & $3,17 \mathrm{E}+06$ \\
\hline 2025 & $2,98 \mathrm{E}+05$ & $3 \%$ & $3,47 \mathrm{E}+06$ \\
\hline 2026 & $3,07 \mathrm{E}+05$ & $3 \%$ & $3,77 \mathrm{E}+06$ \\
\hline 2027 & $3,16 \mathrm{E}+05$ & $3 \%$ & $4,09 \mathrm{E}+06$ \\
\hline 2028 & $3,26 \mathrm{E}+05$ & $3 \%$ & $4,41 \mathrm{E}+06$ \\
2029 & $3,35 \mathrm{E}+05$ & $3 \%$ & $4,75 \mathrm{E}+06$ \\
\hline 2030 & $3,45 \mathrm{E}+05$ & $3 \%$ & $5,10 \mathrm{E}+06$ \\
2031 & $3,56 \mathrm{E}+05$ & $3 \%$ & $5,45 \mathrm{E}+06$ \\
\hline & & &
\end{tabular}

Tabela 8 - Tabela de crescimento do número $\mathrm{N}$

Com a aplicação da equação da AASHTO para o dimensionamento das camadas granulares conforme as equações $7, \quad 8$ e 9 descritas anteriormente.

Dados para dimensionamento do TSD:

1 - CBR do subleito $=8 \%$

2 - CBR da sub-base $=20 \%$

$3-\mathrm{IG}=0$

$4-\mathrm{CBR}$ base $=80 \%$

$5-\mathrm{N} 0=1,97 \mathrm{E}+05$

6 - Espessura do TSD $=2,5 \mathrm{~cm}$

7 - Coeficiente equivalente estrutural do revestimento $\mathrm{Kr}=1,2$

8 - Coeficiente equivalente estrutural da sub-base $\mathrm{Ks}=1,0$

9 - Coeficiente equivalente estrutural da base $\mathrm{Kb}=1,0$

10 - Espessura total do pavimento $\leq 40$ $\mathrm{cm}$

Dimensionamento:

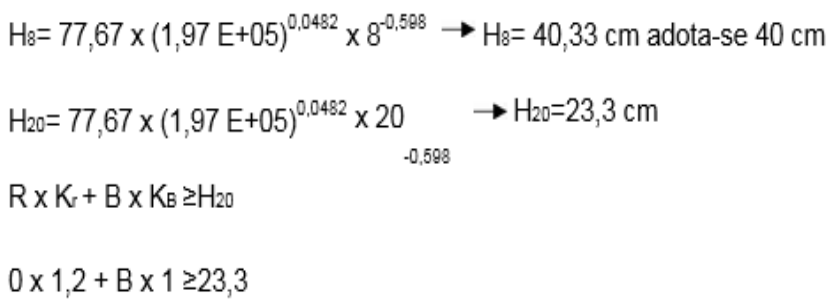

Fixa-se a espessura de base

$\mathrm{B}=20 \mathrm{~cm}$

$\mathrm{R} \times \mathrm{Kr}+\mathrm{B} \times \mathrm{KB}+\mathrm{h} 20 \times \mathrm{Ks} \geq \mathrm{H} 8$

$0 \times 1,2+21,45 \times 1+\mathrm{H} 20 \times 1 \geq 4$

Fixa-se a espessura de sub-base $\mathrm{H} 20=20 \mathrm{~cm}$

Espessura adotada para as camadas de pavimento;

Sub-base

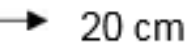

Base

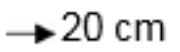

Revestimento

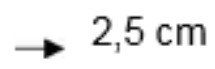

Dados para dimensionamento do CBUQ:

$1-$ CBR do subleito $=8 \%$

2 - CBR da sub-base $=20 \%$

$3-\mathrm{IG}=0$

$4-$ CBR base $=80 \%$

$5-\mathrm{N} 10=2,33 \mathrm{E}+06$

6 - Espessura do TSD $=5 \mathrm{~cm}$

7 - Coeficiente equivalente estrutural do revestimento $\mathrm{Kr}=2,0$

8 - Coeficiente equivalente estrutural da sub-base $\mathrm{Ks}=1,0$

9 - Coeficiente equivalente estrutural da base $\mathrm{Kb}=1,0$

10 - Espessura total do pavimento $\leq 40$ $\mathrm{cm}$

Dimensionamento:

$\mathrm{H}_{8}=77,67 \times(2,33 \mathrm{E}+06)^{0,0482} \times 8^{-0,598} \rightarrow \mathrm{H}_{8}=45 \mathrm{~cm}$ adota-se $40 \mathrm{~cm}$
$\mathrm{H}_{20}=77,67 \times(2,33 \mathrm{E}+06)^{0,0482} \times 2{ }_{-0,598}^{\rightarrow} \rightarrow \mathrm{H}_{20}=26 \mathrm{~cm}$
$\mathrm{R} \times \mathrm{K}+\mathrm{B} \times \mathrm{K}_{\mathrm{B}} \geq \mathrm{H}_{20}$
$5,0 \times 2+\mathrm{B} \times 1 \geq 26$

Fixa-se a espessura de base $\mathrm{B}=16 \mathrm{~cm}$ 
Citação: Veggi E. S., Magalhães S. L. M., Analise comparativa de custos entre concreto betuminoso usinado a quente (CBUQ) e tratamento superficial duplo (TSD). E\&S - Engineering and Science, (2014), 2:1.

$\mathrm{R} \times \mathrm{Kr}+\mathrm{B} \times \mathrm{KB}+\mathrm{h} 20 \times \mathrm{Ks} \geq \mathrm{H} 9$

$5,0 \times 2+16 \times 1+\mathrm{H} 20 \times 1 \geq 45$

Fixa-se a espessura de sub-base $\mathrm{H} 20=19 \mathrm{~cm}$

Espessura adotada para as camadas de pavimento;

$\begin{array}{ll}\text { Sub-base } & \rightarrow 16 \mathrm{~cm} \\ \text { Base } & \rightarrow 19 \mathrm{~cm} \\ \text { Revestimento } & \rightarrow 5 \mathrm{~cm}\end{array}$

Custos

Para uma análise comparativa de custos entre o CBUQ e o TSD, deve-se levar o tempo até que tenhamos as curvas obtidas por relação "custo x tempo".

O DNIT, órgão que faz o controle das rodovias federais em execução, conservação e restauração, elabora por meios estatísticos uma tabela que é denominada Custos Médios

Gerenciais onde têm por base de dados custos de obras em execução, executadas e com contratos de restauração. Tendo como referência o mês de elaboração dessa tabela Setembro de 2012 o custo total para traçar o gráfico de "custos x tempo" será composto da seguinte maneira:

Custo total $=\mathrm{Ce}+\mathrm{Cc}+\mathrm{Cm}$

Ce - Custos de execução inicial leva em consideração a execução das camadas granulares e a execução do revestimento. Para o TSD é o menor custo de execução segundo a tabela e o CBUQ será elaborado o custo proporcional a sua espessura. $\mathrm{O}$

pavimento será de Classe III cm 3,6 m por faixa e $2,5 \mathrm{~m}$ de acostamento conforme Figura 7:
Figura 7 - Seção transversal do pavimento.
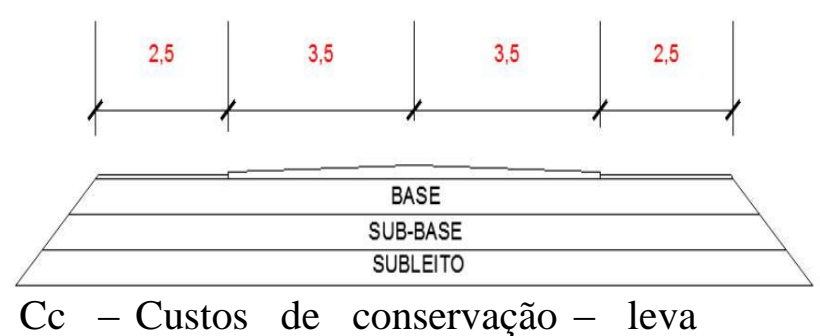

Cc - Custos de conservação - leva em consideração reparos ou outras reformas de acordo com o grau de intensidade especificado no Manual de Conservação do DNIT para TSD e CBUQ. Existem valores obtidos utilizando-se a mesma metodologia dos Manuais de Custos Médios Gerenciais (2006). Neste caso específico, utilizou-se os custos das intervenções dos Estudos de Viabilidade Técnica e Ambiental EVTEA, acrescido de mais $40 \%$ para cobrir as intervenções de pista.

$\mathrm{Cm}$ - Custos de manutenção - leva em consideração a vida útil do pavimento, podendo restaurar ou reconstruir $\mathrm{o}$ pavimento. Para o TSD período de 2 anos se faz a campanha de manutenção leve e após 5 anos a campanha de manutenção pesada e o CBUQ período de 5 anos se faz a campanha de manutenção leve e 10 anos para campanha de manutenção pesada. Caso haja alteração nos valores do número $\mathrm{N}$ que condicione à alteração do tipo de revestimento consequentemente as camadas granulares o custo será de execução não de manutenção.

As planilhas orçamentárias para cada tipo de revestimento analisado foram compostas com a aplicação dos custos unitários das tabelas de Custos Médios Gerenciais de referência setembro de 2012, que é utilizado para todos os custos que irão compor pelos 20 anos. A Tabela 9 mostra os custos de execuções dos pavimentos: 
Citação: Veggi E. S., Magalhães S. L. M., Analise comparativa de custos entre concreto betuminoso usinado a quente (CBUQ) e tratamento superficial duplo (TSD). E\&S - Engineering and Science, (2014), 2:1.

\begin{tabular}{c|c|c|c|c}
\hline Revestimentolserviço & Execuçãa & Conservação & $\begin{array}{c}\text { Manutenç̧̃ã } \\
\text { leve }\end{array}$ & $\begin{array}{c}\text { Manutenção } \\
\text { pesada }\end{array}$ \\
\hline TSD & $2.303 .600,78$ & $18.200,00$ & $329.044,38$ & $1.100 .862,72$ \\
\hline CBUQ & $2.5544 .435,69$ & $31.400,00$ & $427.183,37$ & $1.290 .288,72$ \\
\hline
\end{tabular}

Fonte: DNIT, 2012

Tabela 9 - Custos de execução

\section{Análise de Resultados}

Os pavimentos estudados se diferenciam em características técnicas e custos, porém, sabe-se que os revestimentos se assemelham em suas funções e diferenciam-se em seus métodos de construir, conservar e manter, o que faz com que este trabalho compare as suas semelhanças e os diferencie pelo custo.

$\mathrm{Na}$ comparação de custos $\mathrm{x}$ tempo entre os revestimentos tem-se o TSD como a solução mais vantajosa inicialmente, porém, a diferença de custos entre o CBUQ chega a $11 \%$ a mais, mas sabendo que a capacidade de resistência do CBUQ é maior que do TSD. As espessuras dos pavimentos ficaram com um total um pouco elevado devido à carga que irá trabalhar. Como abordado anteriormente não se utiliza camadas granulares superiores a $40 \mathrm{~cm}$ exceto as camadas de terraplanagem.

As camadas granulares atenderam as condições de resistência, dando suporte aos pavimentos em ambos os dimensionamentos, lembrando que os pavimentos possuem a capacidade de se deformarem em regime elástico, se admitindo, hipoteticamente, deformações permanentes.

Obtendo o custo acumulado total para os pavimentos no período de 20 anos para ambos

os tipos de revestimento conforme a Tabela 10:

\begin{tabular}{c|c} 
Descrição & Custo total do pavimento por km em 20 anos \\
\hline TSD & $\mathrm{R} \$ 6.480 .789,48$ \\
\hline CBUQ & $\mathrm{R} \$ 6.460 .379,87$ \\
\hline
\end{tabular}

Tabela 10 - Custos Finais
Após seguir a tabela do número $\mathrm{N}$ de acordo com sua taxa de crescimento em relação ao tempo e custo do pavimento, tem-se o break even point empatamares, fazendo que por alguns períodos os custos de ambos os métodos de pavimentação se assemelhem entre si, como mostra o Gráfico 2 a seguir:

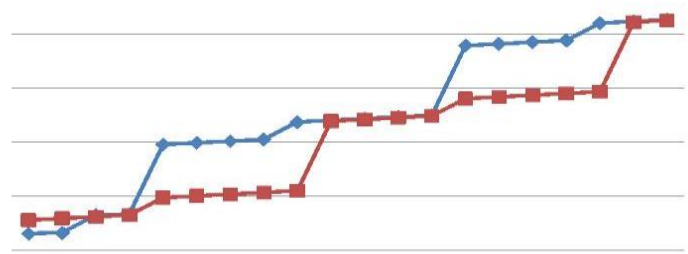

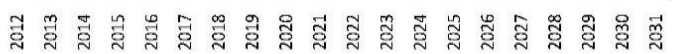

Com̄o se pode verifícar, a ocorrência do ponto de conflito (break even point) não se dá de forma clara e inequívoca. Em certas palavras, o cruzamento dos custos totais no período considerado não ocorreu como o esperado. Isso se deve, em parte, à hipótese adotada para os períodos de projetos proposto, e também ao menu de serviços de para cada tipo de intervenção, como mostra a Tabela 11, quanto às hipóteses estabelecidas, pode-se assinalar:

$\left.1^{a}\right)$ Está refutada, apesar da mínima diferença o TSD como solução inicial é mais caro aos 10 anos.

$\left.2^{a}\right)$ Está refutado, a diferença de custos não estão se equivalendo, obtendo a diferença de $\mathrm{R} \$ \mathbf{8 8 3 . 5 1 4 , 9 6}$ de custos acumulados.

$3^{\text {a }) ~ E s t a ́ ~ c o n f i r m a d a, ~ a o ~ l o n g o ~ d o s ~} 20$ anos o a melhor solução econômica foi a que se iniciou com o CBUQ, obtendo a diferença de $\mathrm{R} \$ 20.409,61$ por $\mathrm{km}$ de pistas de classe III com $3,6 \mathrm{~m}$ a faixa de tráfego e 2,5 $\mathrm{m}$ de acostamento. 


\begin{tabular}{|c|c|c|c|c|c|c|}
\hline Ano & Custo (TSD) & $\begin{array}{l}\text { Custo } \\
\text { acumulado } \\
\text { (TSD) }\end{array}$ & $\begin{array}{l}\text { Serviços } \\
\text { TSD }\end{array}$ & Custo (CBUQ) & \begin{tabular}{|l} 
Custo \\
acumulado \\
(CBUQ)
\end{tabular} & $\begin{array}{l}\text { Serviços } \\
\text { CBUQ }\end{array}$ \\
\hline 2012 & $\begin{array}{l}\text { RS } \\
2.303 .600,78\end{array}$ & $\begin{array}{l}\text { RS } \\
2.303 .600,78\end{array}$ & $\begin{array}{l}\text { Execuçãa } \\
\text { de TSD }\end{array}$ & $\begin{array}{l}\text { RS } \\
2.554 .435,69\end{array}$ & $\begin{array}{l}\text { RS } \\
2.554 .435,69\end{array}$ & $\begin{array}{l}\text { Execução } \\
\text { de CBÜQ }\end{array}$ \\
\hline 013 & \begin{tabular}{|l|} 
RS \\
$18.200,00$
\end{tabular} & \begin{tabular}{|l|} 
RS \\
$2.321 .800,78$
\end{tabular} & Conservaçãa & $\begin{array}{l}\text { RS } \\
31.400,00\end{array}$ & \begin{tabular}{|l|} 
RS \\
$2.585 .835,69$
\end{tabular} & Conservação \\
\hline 2014 & $\begin{array}{l}\text { RS } \\
329.044,38\end{array}$ & $\begin{array}{l}\text { RS } \\
2.650 .845,16\end{array}$ & $\begin{array}{l}\text { Manutenção } \\
\text { leve para } \\
\text { TSD }\end{array}$ & $\begin{array}{l}\text { RS } \\
31.400,00\end{array}$ & $\begin{array}{l}\text { RS } \\
2.617 .235,69\end{array}$ & Conservação \\
\hline 015 & \begin{tabular}{|l} 
RS \\
$18.200,00$
\end{tabular} & $\begin{array}{l}\mathrm{RS} \\
2.669 .045,16\end{array}$ & Conservaçãa & $\begin{array}{l}\text { RS } \\
31.400,00\end{array}$ & $\begin{array}{l}\text { RS } \\
2.648 .635,69\end{array}$ & Conservação \\
\hline 2016 & $\begin{array}{l}\text { RS } \\
1.290 .288,79\end{array}$ & $\begin{array}{l}\text { RS } \\
3.959 .333,95\end{array}$ & $\begin{array}{l}\text { Fresagem + } \\
\text { Execução de } \\
\text { CBUQ }\end{array}$ & R\$ 427.183,37 & $\begin{array}{l}\mathrm{RS} \\
3.075 .819,06\end{array}$ & $\begin{array}{l}\text { Manutençã̃o } \\
\text { leve para } \\
\text { CBUQ }\end{array}$ \\
\hline 017 & $\begin{array}{l}\text { RS } \\
31.400,00\end{array}$ & $\begin{array}{l}\text { RS } \\
\underline{3.990 .733 .95} \\
\end{array}$ & $\underline{\text { Conservação }}$ & $\begin{array}{l}\text { RS } \\
31.400,00\end{array}$ & $\begin{array}{l}\text { RS } \\
\underline{3.107 .219,06} \\
\end{array}$ & Conservação \\
\hline 2018 & $\begin{array}{l}\text { RS } \\
31.400,00\end{array}$ & $\begin{array}{l}\text { RS } \\
4.022 .133,95\end{array}$ & Conservactão & $\begin{array}{l}\text { RS } \\
31.400,00\end{array}$ & $\begin{array}{l}\text { RS } \\
3.138 .619,06\end{array}$ & \\
\hline 2019 & $\begin{array}{l}\text { RS } \\
31.400,00\end{array}$ & $\begin{array}{l}\text { RS } \\
4.053 .533,95\end{array}$ & Conservaçãa & $\begin{array}{l}\text { RS } \\
31.400,00\end{array}$ & $\begin{array}{l}\text { RS } \\
3.170 .019,06\end{array}$ & Conservação \\
\hline 2020 & \begin{tabular}{|l|} 
RS \\
$427.183,37$
\end{tabular} & $\begin{array}{l}\text { RS } \\
4.480 .717,32\end{array}$ & $\begin{array}{l}\text { Manutenção } \\
\text { leve para } \\
\text { CBUQ }\end{array}$ & $\begin{array}{l}\text { RS } \\
31.400,00\end{array}$ & $\begin{array}{l}\text { RS } \\
3.201 .419,06\end{array}$ & Conservação \\
\hline 2021 & $\begin{array}{l}\text { RS } \\
31.400,00\end{array}$ & $\begin{array}{l}\text { RS } \\
4.512 .117,32\end{array}$ & Conservação & $\begin{array}{l}\text { RS } \\
1.290 .288,72\end{array}$ & $\begin{array}{l}\text { RS } \\
4.491 .707,78\end{array}$ & $\begin{array}{l}\text { Manutenção } \\
\text { pesada com } \\
\text { fresagem }\end{array}$ \\
\hline 022 & $\begin{array}{l}\text { RS } \\
31.400,00\end{array}$ & $\begin{array}{l}\text { RS } \\
4.543 .517,32\end{array}$ & Conservaçãa & $\begin{array}{l}\text { RS } \\
31.400,00\end{array}$ & $\begin{array}{l}\text { RS } \\
4.523 .107,78\end{array}$ & Conservação \\
\hline 2023 & $\begin{array}{l}\text { RS } \\
31.400,00\end{array}$ & $\begin{array}{l}\text { RS } \\
4.574 .917,32\end{array}$ & Conservação & $\begin{array}{l}\text { RS } \\
31.400,00\end{array}$ & $\begin{array}{l}\text { RS } \\
4.554 .507,78\end{array}$ & Conservação \\
\hline 2024 & $\begin{array}{l}\text { RS } \\
31.400,00\end{array}$ & $\begin{array}{l}\text { RS } \\
4.606 .317,32\end{array}$ & Conservação & $\begin{array}{l}\text { RS } \\
31.400,00\end{array}$ & \begin{tabular}{|l|} 
RS \\
$4.585 .907,78$
\end{tabular} & Conservaçãa \\
\hline 2025 & $\begin{array}{l}\text { RS } \\
1.290 .288,79\end{array}$ & $\begin{array}{l}\text { RS } \\
5.896 .606,11\end{array}$ & $\begin{array}{l}\text { Manutenção } \\
\text { Pesada com } \\
\text { fresagem }\end{array}$ & RS 427.183,37 & $\begin{array}{l}\text { RS } \\
5.013 .091,15\end{array}$ & $\begin{array}{l}\text { Manutenção } \\
\text { leve para } \\
\text { CBUQ }\end{array}$ \\
\hline 026 & \begin{tabular}{|l} 
RS \\
$31.400,00$
\end{tabular} & $\begin{array}{l}\text { RS } \\
5.928 .006,11\end{array}$ & Conservação & $\begin{array}{l}\text { RS } \\
31.400,00\end{array}$ & $\begin{array}{l}\text { RS } \\
5.044 .491,15\end{array}$ & Conservaçãa \\
\hline 2027 & $\begin{array}{l}\text { RS } \\
31.400,00\end{array}$ & $\begin{array}{l}\text { RS } \\
5.959 .406,11\end{array}$ & Conservaçãa & $\begin{array}{l}\text { R\$ } \\
31.400,00\end{array}$ & \begin{tabular}{|l|} 
RS \\
$5.075 .891,15$
\end{tabular} & Conservação \\
\hline 2028 & $\begin{array}{l}\text { RS } \\
31.400,00\end{array}$ & \begin{tabular}{|l|} 
RS \\
$5.990 .806,11$
\end{tabular} & Conservação & $\begin{array}{l}\text { RS } \\
31.400,00\end{array}$ & \begin{tabular}{|l|} 
RS \\
$5.107 .291,15$
\end{tabular} & Conservação \\
\hline 2029 & \begin{tabular}{|l|} 
RS \\
$427.183,37$
\end{tabular} & $\begin{array}{l}\text { RS } \\
6.417 .989,48\end{array}$ & $\begin{array}{l}\text { Manutenção } \\
\text { leve para } \\
\text { CBUQ }\end{array}$ & \begin{tabular}{|l|} 
RS \\
$31.400,00$
\end{tabular} & $\begin{array}{l}\text { RS } \\
5.138 .691,15\end{array}$ & Conservação \\
\hline 2030 & $\begin{array}{l}\text { RS } \\
31.400,00\end{array}$ & $\begin{array}{l}\text { RS } \\
6.449 .389,48\end{array}$ & Conservação & $\begin{array}{l}\text { RS } \\
1.290 .288,72\end{array}$ & $\begin{array}{l}\text { RS } \\
6.428 .979,87\end{array}$ & $\begin{array}{l}\text { Manutenção } \\
\text { pesada com } \\
\text { fresagem }\end{array}$ \\
\hline 2031 & $\begin{array}{l}\text { RS } \\
31.400,00\end{array}$ & $\begin{array}{l}\text { RS } \\
6.480 .789,48\end{array}$ & Conservação & \begin{tabular}{|l} 
R\$ \\
$31.400,00$
\end{tabular} & $\begin{array}{l}\text { RS } \\
6.460 .379,87\end{array}$ & Conservação \\
\hline
\end{tabular}

Tabela 11 - Custos e serviços

\section{Conclusões e Sugestões}

A análise de custos foi desenvolvida neste trabalho afim de que tenha uma visão clara de custos comparativos de pavimentos flexíveis, análise essa, onde se compara dois métodos distintos, porém com a mesma funcionalidade.

Pelos métodos utilizados pode-se concluir que os pavimentos flexíveis independentemente, possuem custos semelhantes de acordo com a demanda de tráfego utilizada, embora o uso de soluções que atendam demanda maiores em longo prazo é mais econômica.

O CBUQ apesar da pouca diferença de custos é a solução mais econômica e de melhor aceitação, pois necessita menos intervenções que a proposta iniciando com TSD.

Sob aspectos acadêmicos sugere-se que sejam desenvolvida mais desse tema, em particular pavimentação por etapas.

As sugestões para que possam prosseguir um estudo melhor ou mais aprofundado deste trabalho serão: utilizar o número $\mathrm{N}$ inicial valores menores para que haja maior período que atenda o TSD, alterar para 30 anos o período comparativo, fazer comparativo com pavimento rígido, utilizar CBUQ com polímeros modificados para reduzir a espessura de $5 \mathrm{~cm}$ para $4 \mathrm{~cm}$ e possivelmente reduzir o custo total e elaborar mecanismo para fazer mais detalhadamente a composição de custos dos revestimentos buscando a solução economia exata.

\section{Referências}

ASSOCIAÇÃO BRASILEIRA DAS EMPRESAS DISTRIBUIDORAS DE ASFALTO - ABEDA (2001). Manual básico de emulsões asfálticas. Soluções para pavimentar sua cidade. ABEDA. Rio de Janeiro

AGÊNCIA NACIONAL DO PETRÓLEO - ANP (2013)

Disponível em: http://nxt .anp.gov.br/NXT/gateway.dll/leg/resolu coes_anp /2013/ janeiro/ ranp \% 205\%20-\%202013 .xml ?fn =document -frameset.htm $\$ \mathrm{f}=$ templates $\$ 3.0$. Acesso em: 12/05/2013.

BALBO, José Tadeu (2007). Pavimentação asfáltica; matérias, projetos e restauração. Editora Oficina de textos. São Paulo.

BENEVIDES, Sérgio Armando de Sá e (2000). Análise Comparativa dos Métodos de Dimensionamento dos Pavimentos Asfálticos: Empírico do DNER e da Resiliência da COPPE/UFRJ em rodovias do Estado do Ceará. Tese de doutorado COPPE/UFRJ. Rio de Janeiro.

BERNUCCI, L.B.; MOTTA, L.M.G.; CERATTI, J.A.P.; 
Citação: Veggi E. S., Magalhães S. L. M., Analise comparativa de custos entre concreto betuminoso usinado a quente (CBUQ) e tratamento superficial duplo (TSD). E\&S - Engineering and Science, (2014), 2:1.

SOARES; J.B (2008). Pavimentação Asfáltica - Formação Básica para Engenheiros. Petrobras/ABEDA. Rio de Janeiro.

BLÜCHER, Edgard (1980). Mêcanica dos solos para engenheiros - Volume II. Editora Salesianas. São Paulo.

DEPARTAMENTO NACIONAL DE ESTRADAS DE RODAGEM (1997a). DNER-ES 300/97:Pavimentos Flexíveis - Reforço do Subleito Especificação de serviço.

DNER. Rio de Janeiro.

DEPARTAMENTO NACIONAL DE ESTRADAS DE RODAGEM (1997b). DNER-ES 706/1999: Manual de Projeto Geométrico. DNER. Rio de Janeiro.

DEPARTAMENTO NACIONAL DE ESTRADAS DE RODAGEM (1999). DNER-ES 386/99: Pavimento Flexível - Mistura Asfálticas a Quente Especificação de Serviço. DNER. Rio de Janeiro

DEPARTAMENTO NACIONAL DE INFRAESTRUTURA TRANSPORTE (2005). DNIT

710/2005: Manual de Conservação.

DNIT. Rio de Janeiro

DEPARTAMENTO NACIONAL DE INFRAESTRUTURA TRANSPORTE (2006a). DNIT

002/2006: Manual de Drenagem de Rodovias. DNIT. Rio de Janeiro.

DEPARTAMENTO NACIONAL DE INFRAESTRUTURA TRANSPORTE (2006b). DNIT

719/2006: Manual de Pavimentação. DNIT. Rio de Janeiro.

DEPARTAMENTO NACIONAL DE INFRAESTRUTURA TRANSPORTE (2006b). DNIT

719/2006: Manual de Pavimentação. DNIT. Rio de Janeiro.

DEPARTAMENTO NACIONAL DE INFRAESTRUTURA TRANSPORTE (2006c). DNIT

723/2006: Manual de Contagem de Tráfego. DNIT. Rio de Janeiro

DEPARTAMENTO NACIONAL DE INFRAESTRUTURA TRANSPORTE (2006d). DNIT 031/2006- ES: Pavimentação - Concreto Asfáltico -
Especificação de serviço. DNIT. Rio de Janeiro.

DEPARTAMENTO NACIONAL DE INFRAESTRUTURA TRANSPORTE (2009). DNIT 301/2009- ES: Pavimentação - $\quad$ Sub-base Estabilizada Granulometricamente Especificação de serviço. DNIT. Rio de Janeiro.

DEPARTAMENTO NACIONAL DE INFRAESTRUTURA TRANSPORTE (2010a). DNIT 141/2010- ES Pavimentação Base Estabilizada Granulometricamente - Especificação de serviço. DNIT. Rio de Janeiro.

DEPARTAMENTO NACIONAL DE INFRAESTRUTURA TRANSPORTE (2010b). DNIT 137/2010- ES: Pavimentação - Regularização do Subleito - Especificação de serviço.

DNIT. Rio de Janeiro.

DEL BARCO, Carlos (2006). Disponível em: http://aprendendoagostardehistoria. blogspot.com.br/p/idade-antiga.html. Acesso em: 23/01/2013.

FERREIRA, Davi Hoffmann (2011). Análise da resistência de misturas de CBUQ pelo método Marshall com utilização de agregados de Nobres/MT. Trabalho de Graduação FAET/UFMT. Cuiabá.

MEDINA, Jacques de (1997), Mecânica dos Pavimentos. Ed. UFRJ. Rio de Janeiro.

PINTO, Salomão (1991). Estudo do comportamento à Fadiga de Misturas Betuminosas e aplicação na Avaliação Estrutural de Pavimentos. Tese de doutorado COPPE/UFRJ. Rio de Janeiro. 